\title{
USOS DOS ÍNDICES PET E UTCI NA AVALIAÇÃO DO CONFORTO TERMAL NO CAMPUS DA UFMT EM CUIABÁ-MT
}

\author{
Paulo Celso do Couto Nince \\ Doutorando em Física Ambiental, Linha de Pesquisa: Análise Microclimática em Sistemas Urbanos, E-mail: \\ pnince@ig.com.br
}

\section{Carlo Ralph de Musis}

Professor do Programa de Pós-Graduação em Física Ambiental, Linha de Pesquisa: Análise Microclimática em Sistemas Urbanos, E-mail: carlo.demusis@gmail.com

\section{Marcelo Sacardi Biudes}

Professor do Instituto de Física/ IF/ UFMT, Professor do Programa de Pós-Graduação em Física Ambiental, Linha de Pesquisa: Análise Microclimática em Sistemas Urbanos, E-mail: marcelo.biudes@gmail.com

José de Souza Nogueira

Professor do Departamento de Física e Coordenador do Programa de Pós-Graduação em Física Ambiental, E-mail: nogueira@ufmt.com.br

\section{Marta Cristina de Jesus Albuquerque Nogueira}

Professora do Departamento de Arquitetura e Urbanismo/ FAET/ UFMT, Professora do Programa de Pós-Graduação em Física Ambiental, Linha de Pesquisa: Análise Microclimática em Sistemas Urbanos, E-mail: mcjanp@gmail.com

http://dx.doi.org/10.5902/223611707707

\section{RESUMO:}

Procedimentos existentes para a avaliação do ambiente térmico nas áreas meteorologia, saúde, planejamento, turismo e recreação e pesquisa climática apresentam deficiências significativas. Höppe (1999) definiu o índice, temperatura equivalente fisiológica, (PET). A Comissão da Sociedade Internacional de Biometeorologia desenvolveu o Índice Climático Térmico Universal (UTCI). Esta artigo investiga as variáveis temperatura e umidade do ar e os índices PET e UTCI para identificar a que classes de estresse térmicos estão submetidos os usuários do campus da UFMT em diferentes tipos de revestimentos do solo e a vegetação nas condições do microclima em Cuiabá, Brasil. Para isto envolveu medidas micrometeorológicas em quatro pontos do campus durante 43 dias contínuos em dois períodos: quente chuvoso e outro quente seco no ano de 2012. A sombra da mangueira durante o dia constatou-se: (i) as menores Tbs se comparadas com as Tbs dos outros pontos; (ii) as maiores umidades relativas; (iii) o PET bem menor, nos dois períodos de medição, que os outros pontos de medição; (iv) o UTCI com índice inferior a $35^{\circ} \mathrm{C}$ dentro da faixa de estresse de calor moderado. Logo se vê a importância de proporcionar sombreamento nos espaços abertos em climas tropicais. Como o PET ultrapassou o valor de $50^{\circ} \mathrm{C}$, nos dois períodos, nas horas críticas, portanto, atinge o estresse de calor extremo. A grama, o concreto e o asfalto, no período diurno das 10 às $17 \mathrm{~h}$ apresentam índices até $43^{\circ} \mathrm{C}$, dentro da faixa de estresse de calor muito forte, porém não atingem a faixa do estresse de calor extremo.

Palavras-chave: bioclimatologia, PET e UTCI. 


\section{ABSTRACT:}

Existing procedures for evaluating the thermal environment in the areas weather, health, planning, tourism and recreation and climate research have significant deficiencies. Hoppe (1999) defined the index, physiological equivalent temperature (PET). The Commission of the International Society of Biometeorology developed the Universal Thermal Climate Index (UTCI). This paper investigates the variables temperature and humidity and indexes PET and UTCI to identify the classes that are subject to thermal stress users of campus UFMT in different types of coatings soil and vegetation conditions of the microclimate in Cuiabá, Brazil. To this involved micrometeorological measurements at four points on campus for 43 continuous days during two periods: rainy and hot in a warm dry year 2012. The shadow of the hose during the day it was found: (i) the smaller Tbs Tbs as compared with those of the other points, (ii) the greatest relative humidity, (iii) PET is much lower in two measurement periods, the other measuring points, (iv) the UTCl with index less than $35^{\circ} \mathrm{C}$ within the range of mild heat stress. Soon we see the importance of providing shade in open spaces in tropical climates. As PET has exceeded the value of $50^{\circ} \mathrm{C}$, in both periods in critical hours therefore achieves the stress of extreme heat. The grass, concrete and asphalt during the day from 10 to $17 \mathrm{~h}$ had rates up to $43^{\circ} \mathrm{C}$, within the range of heat stress very strong, but do not reach the age of extreme heat stress.

Keywords: bioclimatology, PET and UTCl.

\section{INTRODUÇÃO}

A produção brasileira sobre o clima urbano foi em grande parte realizada por geógrafos, partindo da contribuição teórica de Monteiro (1976) apud Assis (2005), que aborda o clima urbano como sistema a partir dos canais da percepção humana (conforto térmico, qualidade do ar e impacto meteórico). Dez anos depois da publicação de Teoria e Clima Urbano, o autor, ao analisar criticamente a produção brasileira naquele período, já chamava a atenção para a necessidade de diversificação dos estudos urbanos nos vários sistemas climáticos do país, bem como do desenvolvimento de modelagem para a simulação, tomando por base as situações observadas (MONTEIRO, 1986, apud ASSIS, 2005). Assis (2005) acrescenta que Maitelli (1994) foi quem primeiro apresentou um trabalho lidando com a perspectiva do balanço de energia em área urbana em Cuiabá/MT, investigando os efeitos da urbanização na temperatura e umidade do ar na cidade, sendo este um dos poucos estudos em área continental do país. As medidas do balanço de energia no centro urbano mostraram altas taxas de calor armazenado, sendo que os comportamentos das variáveis do balanço puderam explicar aspectos da ilha de calor e do regime de umidade na cidade. Duarte (2002) apud Assis (2005) verificou o grau de correlação entre variáveis mais ligadas à legislação urbana, tais como a taxa de ocupação, o coeficiente de aproveitamento, a presença de água e de vegetação, com a temperatura do ar na cidade de Cuiabá, MT.

O estudo do conforto térmico surgiu com a necessidade de condicionamento de ambientes fechados para um melhor rendimento das atividades humanas, especialmente no trabalho. Mais recentemente, a busca de estratégias bioclimáticas para a melhoria da eficiência energética das edificações e a preocupação com a qualidade dos espaços livres públicos vieram a desencadear maior interesse no conforto térmico em espaços abertos.

A ASHRAE (2004) define Conforto Térmico como a condição da mente de um indivíduo que expressa satisfação como o meio ambiente termal onde se encontra. Como há grandes 
variações fisiologicamente e psicologicamente de pessoas para pessoas, é difícil satisfazer a todos num mesmo espaço. Höppe (1999) propôs o Modelo de Munich, baseando-se também na equação de balanço térmico, mas considerando o modelo de dois nós de Gagge (1986) apud Assis (2005) e definiu o índice, temperatura equivalente fisiológica, cujo nome e sigla em inglês são Physiological Equivalente Temperature (PET) e o declarou como um índice universal para a avaliação biometeorológica do meio ambiente termal. Também estudos recentes indicam que o PET é a escolha mais adequada para avaliar as condições de conforto térmico dos ambientes ao ar livre, devido à consideração da interrelação entre balanço de energia do corpo humano e de radiação de onda curta. "PET é definida como a temperatura equivalente fisiológica para qualquer dado lugar (ao ar livre ou dentro de casa) e é equivalente a temperatura do ar na qual, num cenário típico interior, o balanço térmico do corpo humano é mantido com as temperaturas centrais e as da pele iguais para aquelas condições que estão sendo avaliadas.

Procedimentos existentes para a avaliação do ambiente térmico nas áreas de serviços públicos meteorológicos, sistemas públicos de saúde, planejamento de precaução, planejamento urbano, turismo e recreação e pesquisa de impacto climática apresentam deficiências significativas. Isso é mais evidente para índices simples (Principalmente de dois parâmetros), quando são comparados para completar os modelos de balanço de calor desenvolvidos desde 1960. AComissão da Sociedade Internacional de Biometeorologia (ISB - International Society of Biometeorology) desenvolveu o Índice Climático Térmico Universal (UTCI) com base no mais avançado modelo multi-nó da termorregulação que representa progresso na ciência nas últimas três ou quatro décadas, tanto em termo-fisiológico como em teoria de troca de calor (JENDRITZKY et al.2011).

O UTCl abrange as seguintes faixas climáticas: $-50 \circ \mathrm{C} \leq \mathrm{Ta} \leq 50 \circ \mathrm{C},-30 \circ \mathrm{C} \leq \mathrm{Trm}-\mathrm{Ta} \leq 70 \circ \mathrm{C}$, velocidade de vento entre 0,5 e $30,3 \mathrm{~m} / \mathrm{s}$ e umidade relativa de $5 \%$ a $100 \%$ (pressão de vapor máxima $5 \mathrm{kPa}$ ). Assim, a temperatura UTCl é equivalente para dada combinação das variáveis climáticas (vento, radiação, umidade e temperatura do ar) e é definida como a temperatura do ar do ambiente de referência, que produz o mesmo valor de estresse térmico do ambiente real. Segue-se a tabela 01 para classificação dos períodos de medição desta pesquisa.

Tabela 01 - Comparação dos índices UTCI( $\left.{ }^{\circ} \mathrm{C}\right)$ e PET(으)

\begin{tabular}{c|l|l}
\hline Faixa de UTCl $\left({ }^{\circ} \mathbf{C}\right)$ & Faixa de PET $\left({ }^{\circ} \mathbf{C}\right)$ & Categoria de estresse \\
\hline Acima de +46 & Acima de +41 & Estresse de calor extremo \\
\hline$+38 a+46$ & $+35 a+41$ & Estresse de calor muito forte \\
\hline$+32 a+38$ & $+29 a+35$ & Estresse de calor forte \\
\hline$+26 a+32$ & $+23 a+29$ & Estresse de calor moderado \\
\hline$+9 a+26$ & $+18 a+23$ & Nenhum estresse \\
\hline+9 a 0 & $+13 a+18$ & Estresse de frio leve \\
\hline 0 a -13 & $+8 a+13$ & Estresse de frio moderado \\
\hline-13 a -27 & $+4 a+8$ & Estresse de frio forte \\
\hline-27 a -40 & - & Estresse de frio muito forte \\
\hline Abaixo de -40 & Abaixo de +4 & Estresse de frio extremo \\
\hline
\end{tabular}

Fonte: PANAGIOTIS, T.; NASTOS, P.T.; MATZARAKIS, A. (2011)

\section{MATERIAIS E MÉTODO}

\subsection{Local}

A pesquisa foi desenvolvida no ambiente urbano da Cuiabá, Mato Grosso, que conta com cerca de 551.310 habitantes (IBGE, 2011) sendo que a região metropolitana da Grande Cuiabá 
ultrapassa 1 milhão de habitantes e localiza-se na porção Centro-Sul do Estado, no limite ocidental dos domínios do Cerrado e próximo à borda leste do Pantanal Mato-grossense. Atualmente, possui cerca de $3538,17 \mathrm{~km}^{2}$, sendo que $254,57 \mathrm{~km}^{2}$ correspondem à área de macrozona urbana e $3.283,60 \mathrm{~km}^{2}$ à área rural. Encontra-se localizada na província geomorfológica denominada Baixada Cuiabana. As altitudes variam de 146 a 259 metros (IPDU, 2009). A cobertura vegetal é constituída por remanescentes de cerrado, cerradão, matas ciliares no entorno dos rios, e por vegetação exótica (Figura 01).

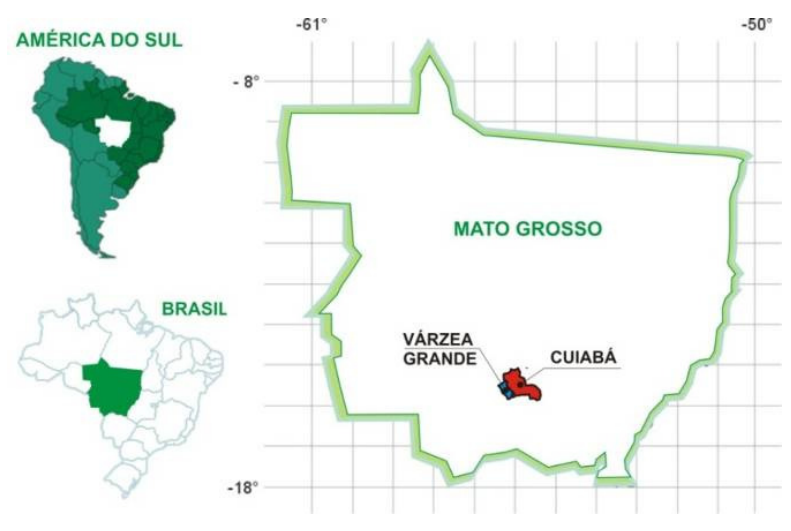

Figura. 01 Localização da região do estudo

Fonte: Oliveira (2011)

O clima dominante é do tipo tropical semi-úmido (classificação Aw de Köppen), sendo a sua principal característica a presença constante de temperaturas elevadas, registrando média anual em torno de $25 \circ \mathrm{C}$ a $26^{\circ} \mathrm{C}$, com duas estações bem definidas: uma seca (outono-inverno) e uma chuvosa (primavera-verão) (MAITELLI, 1994). O índice pluviométrico anual varia de 1.250 a 1.500 mm (CAMPELO JUNIOR et al, 1991). Para Duarte (2000), o clima da região é definido por três períodos: uma estação seca e mais fresca no inverno; uma estação de transição seca e mais quente, um pouco antes das chuvas e, uma estação úmida e quente, durante as chuvas do verão.

A área urbana selecionada para estudo se localiza no campus da Universidade Federal de Mato Grosso (UFMT), que possui 74 hectares, sendo caracterizado por um ambiente heterogêneo, com diferentes tipos de uso e ocupação do solo. Para a pesquisa foram selecionados quatro pontos de interesse no campus: (a) ambiente sombreado por vegetação arbórea (mangueira; Mangifera indica), (b) ambiente coberto por grama do tipo Batatais (Paspalumnotatun) localizado no campo de futebol, (c) ambiente das quadras poliesportivas com predominância de pavimento de concreto (c) e (d) estacionamento do parque aquático com predominância de pavimento asfáltico (Figura 02). Estes pontos foram escolhidos com intuito de avaliar o comportamento destas superfícies e pavimentos sob o ponto de vista do conforto térmico para pedestres que por ventura estejam de passagem por estes ambientes. 


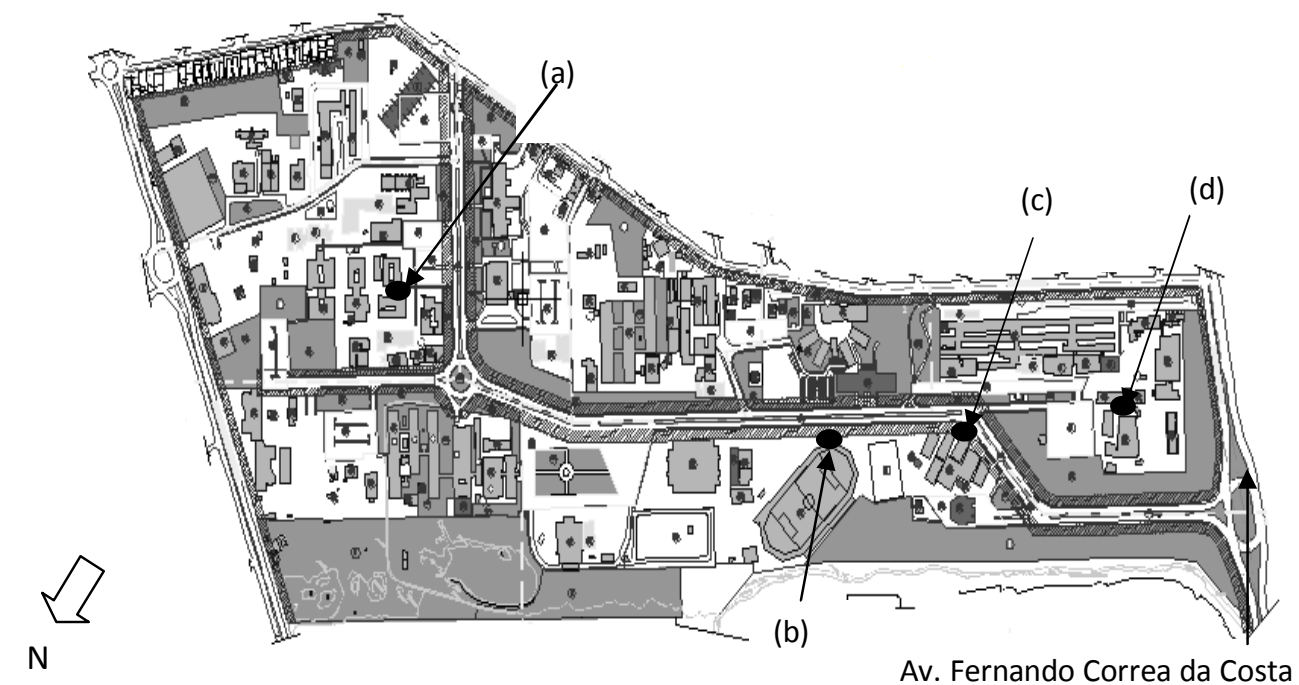

Figura 02 - Locação dos 4 pontos na planta do campus Cuiabá da UFMT Fonte: Callejas et al. 2012

\subsection{Materiais}

A temperatura e umidade do ar foram medidas por registrador automático, marca HOBO, modelo U13, disposto no interior de abrigo meteorológico a 1,5m de altura em relação ao nível do solo. No canal externo do registrador foi monitorado a temperatura de globo utilizando-se uma esfera de plástico de 2,5" de diâmetro (Souza et al., 2002), fixada em suporte na parte superior do abrigo a 1,8m de altura em relação ao nível do solo (Figura 03).

A velocidade do ar nos períodos de coleta foi obtida no sítio que fornece dados metereológicos intitulado Histórico para Cuiabá Marechal Ron, Brazil. A sensação de conforto térmico foi avaliada pelos índices PET e UTCl, utilizando-se o software RayMan Pro, desenvolvido por Matzarakis et al. (2011), cujos dados de entrada foram as coordenadas geográficas e altitude de cada ponto de coleta, umidade relativa do ar (UR), temperatura do ar (Tbs), velocidade do vento (v) e temperatura radiante calculada (Trm) conforme ISO 7726 (INTERNATIONAL...,1998).

Para as características físicas das pessoas, adotaram-se para pedestres masculinos, a saber: altura de $1,70 \mathrm{~m}$, peso de $70 \mathrm{~kg}$, e pedestres femininos: altura de $1,60 \mathrm{~m}$ peso de $60 \mathrm{~kg}$ e para ambos os sexos: vestimenta de 0,5 clo que corresponde a pessoa usando vestimenta leve de verão, ou seja cuecas ou calcinhas, calças longas leves, camisas abertas no pescoço com mangas curtas, meias e calçados leves e atividade de caminhada lenta com taxa metabólica de $135 \mathrm{~W}$, ou seja, pessoa andando a $4 \mathrm{~km} / \mathrm{h}$. Foram realizados dois períodos iguais de coleta de 43 dias consecutivos: (a) a primeira medição no período representativo da estação climática quente-úmida foi de 14 de fevereiro a 27 de março de 2012; e (b) a segunda medição no período representativo da estação climática quente-seca foi de 28 de julho a 08 de setembro de 2012. 


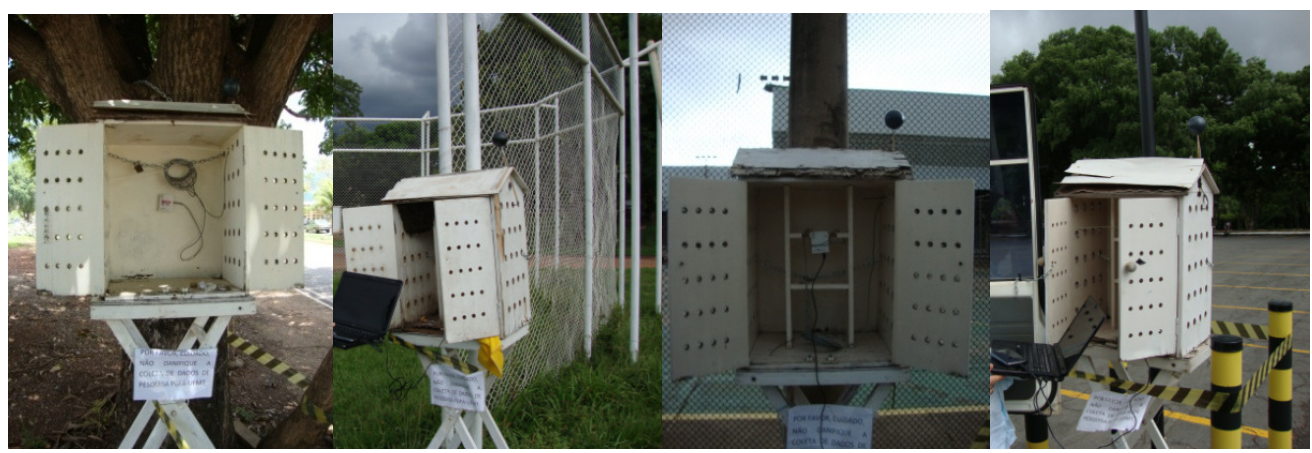

(a)

(b)

(c)

(d)

Figura. 03 Abrigos meteorológicos instalados sob a copa de Mangueira (Mangifera indica) (a), sobre a superfície gramada (Batatais - Paspalum notatun) no campo de futebol (b), sobre o pavimento de concreto nas quadras poliesportivas (c) e sobre o pavimento asfáltico no estacionamento do parque aquático

Fonte: Próprio autor

\section{RESULTADOS E DISCUSSÕES}

As temperaturas de bulbo seco médias na estação quente úmida nos quatros pontos permitem algumas comparações entre si e com a estação quente seca. À noite a grama apresenta as menores temperaturas do ar, mas ultrapassa a sombra da mangueira durante o dia, nas duas estações. O ponto do concreto, no período matutino, ganha mais energia térmica que outros pontos de medição e no vespertino e à noite o ponto da grama perde esta energia mais rapidamente que os outros pontos. Em todos os pontos a Tbs média máxima ocorreu às $14 \mathrm{~h}$ e mínima às $06 \mathrm{~h}$. Às $17 \mathrm{~h}$, as Tbs médias, no período úmido, estão aproximadamente $30^{\circ} \mathrm{C}$ enquanto no período seco estão em torno de $34^{\circ} \mathrm{C}$. Às $08 \mathrm{~h}$ no período úmido, as Tbs médias estão aproximadamente $26^{\circ} \mathrm{C}$ enquanto que no período seco estão em torno de 24 으. O período seco tem maior amplitude que o úmido, pois no período seco há poucas nuvens fazendo que no período noturno a perda de energia térmica seja maior que no úmido. A sombra da mangueira durante o dia constatou-se as menores Tbs se comparadas com as Tbs dos outros pontos. A Tbs máxima no primeiro período foi de $35^{\circ} \mathrm{C}$ e de $39,66^{\circ} \mathrm{C}$ segundo, (Figura 04).
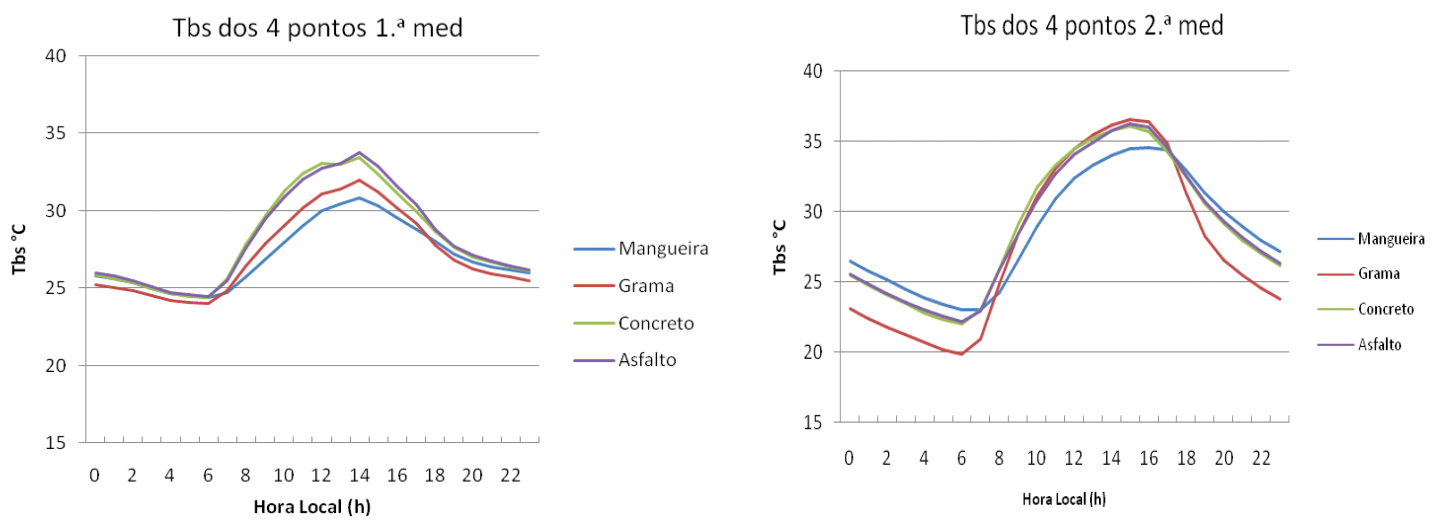
Figura 04 - Comparação das Tbs dos 4 pontos das 1. ${ }^{a}$ e 2. ${ }^{a}$ medições

Fonte: Próprio autor

Quanto a umidade relativa do ar média aconteceu o inverso da Tbs com era de se esperar máxima às $06 \mathrm{~h}$ e mínima as $14 \mathrm{~h}$ em todos os pontos de medição. A ordem decrescente de umidade relativa média nos quatro pontos foram grama, mangueira, concreto e asfalto, observando que na madrugada o concreto supera a mangueira. Comparando a umidade relativa dos dois períodos, observa-se que o úmido ela variou de $50 \%$ a $90 \%$ enquanto no período seco de $25 \%$ a $68 \%$ justificando a denominação dos dois períodos úmido e seco e ambos quentes com Tbs média variando de $27,09^{\circ} \mathrm{C}$ a $28,86^{\circ}$ (Figura 05).
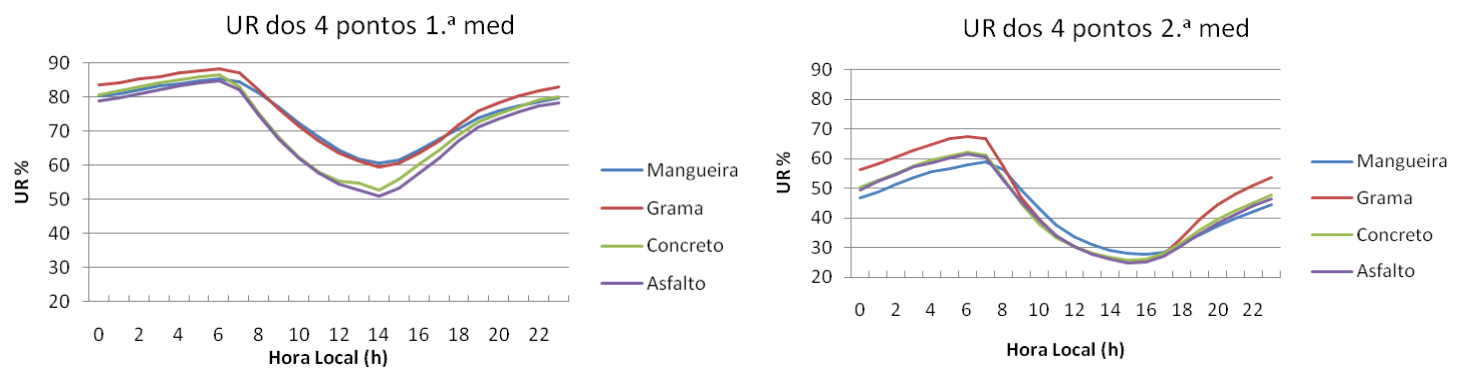

Figura 05 - Comparação das UR dos 4 pontos das $1 .^{a}$ e $2 .^{a}$ medições

Fonte: Próprio autor

O índice PET habilita a uma pessoa a comparar os efeitos integrais das condições termais externas coma sua própria experiência interna. Por exemplo, às10h no ponto grama da segunda medição indicava um índice PET médio de $41,8^{\circ} \mathrm{C}$, isto significa que um ocupante de uma sala com temperatura do ar a $41,8^{\circ} \mathrm{C}$ sentiria a mesma sensação térmica nas condições externas. Utilizando a Tabela 01 do índice PET apresentado por Panagiotis, Nastos, Matzarakis (2011), observa-se que a faixa de $18-23$ do $\operatorname{PET}\left({ }^{\circ} \mathrm{C}\right)$ como percepção térmica neutra ou confortável somente no período noturno das $19 \mathrm{~h}$ às $07 \mathrm{~h}$, os PET calculados, nos dois períodos, estão dentro desta faixa. Ou seja, somente à noite há possibilidade de conseguir a faixa conforto térmico.

Como o PET ultrapassou o valor de $50^{\circ} \mathrm{C}$, nos dois períodos, nas horas críticas, portanto, atinge o estresse de calor extremo. No período diurno à sombra da mangueira o PET é bem menor, nos dois períodos de medição, que os outros pontos de medição, atingindo o máximo de 35,4 으 às $15 \mathrm{~h}$ no segundo período. Esta constatação, também faz Hirashima (2010): estar à sombra pode ser uma ação de conforto adaptativo frequentemente utilizada para minimizar as influências das altas temperaturas radiantes médias encontradas ao sol e que aumentam significativamente os valores do PET. Esta constatação pode vir a confirmar a importância de proporcionar sombreamento nos espaços abertos em climas tropicais (Figura 06). 

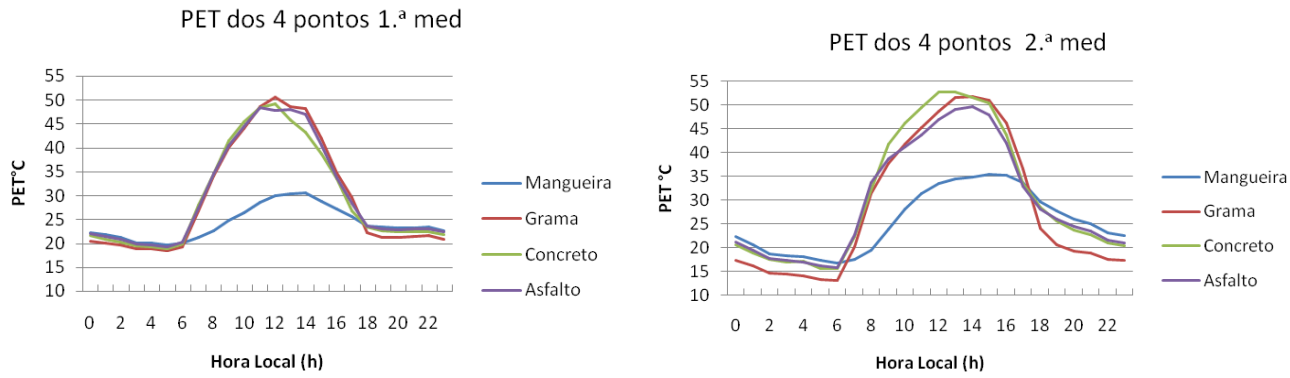

Figura 06 - Comparação dos PET dos 4 pontos das $1 .^{\mathrm{a}}$ e $2 .^{\mathrm{a}}$ medições

Fonte: Próprio autor

Continuando a utilização da Tabela 01 de Panagiotis, Nastos, Matzarakis (2011) na coluna do UTCI para avaliar os quatros pontos nas duas medições, verifica-se que em média os quatros pontos na segunda medição das $02 \mathrm{~h}$ às $06 \mathrm{~h}$ apresentam na faixa de $9^{\circ} \mathrm{C}$ a $26^{\circ} \mathrm{C}$ do índice UTCl correspondendo a categoria de sem estresse térmico. O período noturno nas duas medições e nos quatro pontos apresenta-se na faixa de UTCI de $26^{\circ} \mathrm{C}$ a $32^{\circ} \mathrm{C}$ correspondendo ao estresse de calor moderado. A grama, o concreto e o asfalto, no período diurno das $10 \mathrm{~h}$ às $17 \mathrm{~h}$ apresentam índices até $43^{\circ} \mathrm{C}$, dentro da faixa de estresse de calor muito forte, porém não atingem a faixa do estresse de calor extremo. Novamente o sombreamento da mangueira apresenta índice inferior a $35^{\circ} \mathrm{C}$ dentro da faixa de estresse de calor moderado (Figura 07).
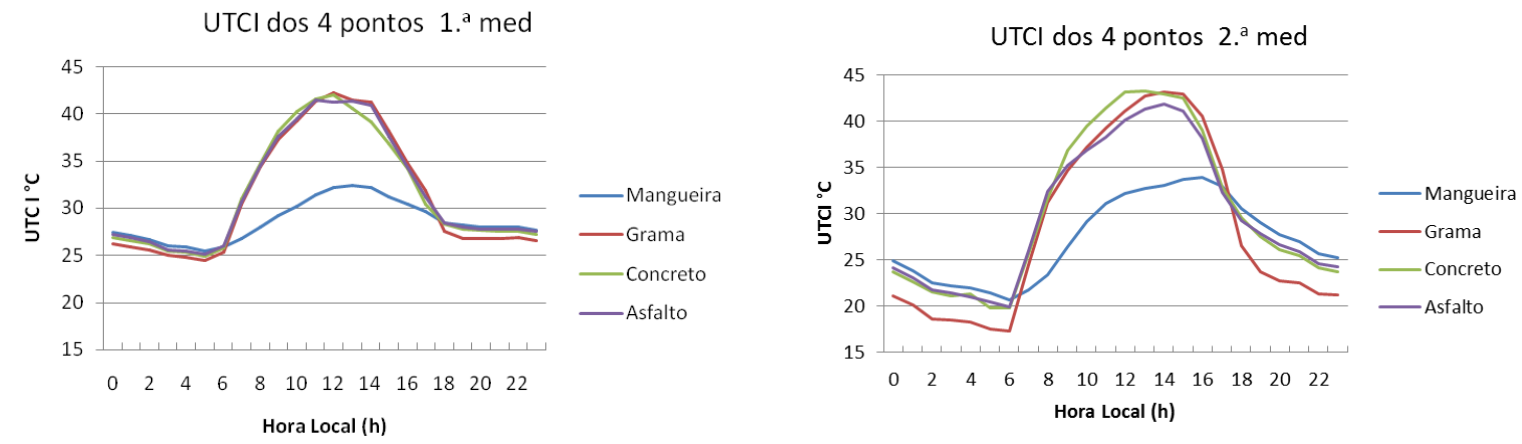

Figura 07 - Comparação dos UTCI dos 4 pontos das $1^{\mathrm{a}}$ e $2^{\mathrm{a}}$ medições

Fonte: Próprio autor

\section{CONSIDERAÇÕES FINAIS}

A sombra da mangueira durante o dia constatou-se: (i) as menores Tbs se comparadas com as Tbs dos outros pontos; (ii) as maiores umidades relativas; (iii) o PET bem menor, nos dois períodos de medição, que os outros pontos de medição; (iv) o UTCl com índice inferior a $35^{\circ} \mathrm{C}$ dentro da faixa de estresse de calor moderado. Estas constatações podem vir a confirmar a importância de proporcionar sombreamento nos espaços abertos em climas tropicais. Como o PET ultrapassou o valor de $50^{\circ} \mathrm{C}$, nos dois períodos, nas horas críticas, portanto, atinge o estresse de calor extremo. A grama, o concreto e o asfalto, no período diurno das $10 \mathrm{~h}$ às $17 \mathrm{~h}$ apresentam 
índices até $43^{\circ} \mathrm{C}$, dentro da faixa de estresse de calor muito forte, porém não atingem a faixa do estresse de calor extremo.

\section{AGRADECIMENTOS} logística.

Os autores agradecem a ELETROBRAS pelo apoio financeiro e ao PGFA/ UFMT pela

\section{REFERÊNCIAS BIBLIOGRÁFICAS}

ASHRAE. Thermal environmental conditions for human occupancy. ANSI/ASHRAE Standard 55-2004.

ASSIS, E. S. A abordagem do clima urbano e aplicações no planejamento da cidade:reflexões sobre uma trajetória. IN: Encac-elacac 2005 Maceió/ Alagoas/ Brasil. Disponível em <Erro! A referência de hiperlink não é válida.> Acesso em 29 out. 2012.

CALLEJAS, I. J. A.; NINCE, P. C. C.; DURANTE, L. C.; NOGUEIRA, M. C. J. A. Vegetação, pavimentos urbanos e suas implicações na sensação térmica dos pedestres. In: PLURIS 2012, V Congresso Luso-Brasileiro para o planejamento urbano, regional, integrado e sustentável, 2012. Brasília/ DF.

CAMPELO JUNIOR, J. H.; PRIANTE FILHO, N.; CASEIRO, F. T. Caracterização macroclimática de Cuiabá. III In: Encontro Nacional de Estudos sobre o Meio Ambiente, Londrina. Anais. 1991. Londrina/ PR, 1991.

DUARTE, D. H. S. Padrões de Ocupação do Solo e Microclimas Urbanos Na Região de Tropical Continental. 2000. 278f. Tese (Doutorado em Arquitetura) - Universidade de São Paulo, São Paulo/ SP.

HIRASHIMA,S. Q. S.; ASSIS, E. S.; FERREIRA, D. G. Calibração do índice de conforto térmico temperatura equivalente fisiológica (pet)para espaços abertos do município de Belo Horizonte MG. . In: XI ENCAC, VII ELACAC, 2011, Búzios/ RJ.

HÖPPE, P. The physiological equivalent temperature - a universal índex for the biometeorological assessment of the thermal environment. Int J Biometeorol, n. 43, p.71-75, 1999.

IBGE. Instituto Brasileiro de Geografia e Estatística. Disponível em: <http://www.ibge.gov.br>. Acesso em 10 abril, 2011.

IPDU. Instituto de Pesquisas e Desenvolvimento Urbano. Perfil Socioeconômico de Cuiabá, V. IV. Cuiabá: Central de Texto, 2009.

JENDRITZKY, G.; DE DEAR, R.; HAVENITH, G. UTCI - why another thermal index? International Journal of Biometeorology, 56 (3), pp. $421-428.2012$ 
MAITTELLI, G. T. Uma Abordagem Tridimensional de Clima Urbano em Área Tropical Continental. O Exemplo de Cuiabá - MT. Tese de Doutorado (Faculdade de Filosofia e Ciências Humanas), Universidade de São Paulo. 1994.

MATZARAKIS, A.; RUTZ, F.; MAYER, H. ,Aplicativo computacional Ray Man 1.2. Disponível: www.mif.unifreiburg.de/rayman/2000, Acesso 10 abr. 2011.

PANAGIOTIS, T.; NASTOS, P.T.; MATZARAKIS, A. The effect of air temperature and human thermal indices on mortality in Athens, Greece. Theor Appl Climatol 108:591-599. 2012.

Identificação dos Autores:

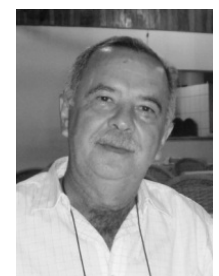

\section{Paulo Celso do Couto Nince}

Graduação em Engenharia Civil pela Universidade Federal de Mato Grosso/ UFMT

Professor Efetivo do Departamento de Engenharia Civil/ UFMT;

Doutorando pelo Programa de Pós Graduação em Física Ambiental/ PPGFA/ UFMT, Linha de Pesquisa: Análise

Microclimática em Sistemas Urbanos, E-mail: pnince@ig.com.br

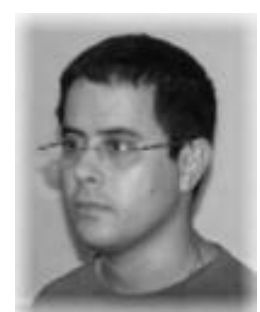

Carlo Ralph De Musis

Graduação em Engenharia Civil pela Universidade Federal de Mato Grosso/ UFMT;

Professor Efetivo da Universidade de Cuiabá/ UNIC;

Professor do Programa de Pós-Graduação em Física Ambiental, Linha de Pesquisa: Análise Microclimática em Sistemas Urbanos, E-mail: carlo.demusis@gmail.com

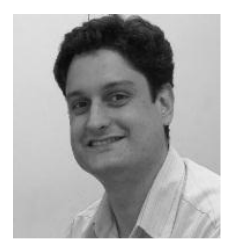

\section{Marcelo Sacardi Biudes}

Graduação em Licenciatura Plena em Física pela Universidade Federal de Mato Grosso/ UFMT; Professor Efetivo do Instituto de Física/ UFMT;

Professor do Programa de Pós Graduação em Física Ambiental/ PPGFA/ UFMT, Linha de Pesquisa: Análise Microclimática em Sistemas Urbanos, E-mail: marcelo.biudes@gmail.com 


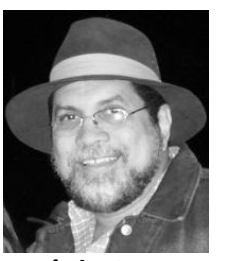

José de Souza Nogueira

Graduação em Licenciatura Plena em Física pela Universidade Federal de Mato Grosso/ UFMT;

Professor Efetivo do Instituto de Física/ UFMT;

Professor do Programa de Pós-Graduação em Física Ambiental e Coordenador do Programa de Pós-Graduação em Física Ambiental em nível de Mestrado e Doutorado, E-mail: nogueira@ufmt.br

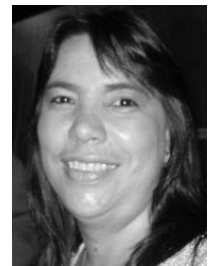

Marta Cristina de Jesus Albuquerque Nogueira

Graduação em Engenharia Civil pela Universidade Federal de Mato Grosso/ UFMT;

Professor Efetiva do Departamento de Arquitetura e Urbanismo/ UFMT;

Professora do Programa de Pós Graduação em Física Ambiental/ PPGFA/ UFMT, Linha de Pesquisa: Análise Microclimática em Sistemas Urbanos, E-mail: mcjanp@gmail.com 